\title{
A DON. LUIS CIFUENTES DELATTE: MAESTRO, ACADÉMICO, CIENTÍFICO Y FIGURA DE LA UROLOGÍA.
}

\author{
Armando Zulvaga Gómez
}

Servicio de Urología. Hospital Clínico San Cecilio. Granada. España.

Resumen.- El autor describe alguna de sus vivencias con su maestro Don Luis Cifuentes Delatte. Destaca la personalidad científica, académica y asistencial del Profesor Cifuentes, una de las figuras más importantes de la urología española del siglo XX.

Palabras clave: Personalidad urológica. Académica. Científica. Luis Cifuentes Delatte.
Armando Zuluaga Gómez

Servicio de Urología

Hospital Clínico San Cecilio.

Granada. (España).

azulvagagomez@hotmail.com
Summary.- The author describes some of his life experiences with his professor Dr. Luis Cifuentes Delatte. We emphasize the scientific, academic and clinical personality of Professor Cifuentes, one of the most important personalities in the Spanish Urology during the 20th century.

Keywords: Urological Personality. Academic personality. Scientific personality. Dr. Luis Cifuentes Delatte.

\section{INTRODUCCIÓN}

Los responsables de este número monográfico en recuerdo y homenaje a D. Luis Cifuentes Delatte me piden unas líneas de colaboración recordando al maestro que fue $D$. Luis. Como discípulo me enorgullece, pero temo no conseguir plasmar todo lo que verdaderamente se merece la figura de un hombre que fue referente en los foros nacionales e internacionales de la urología del siglo XX.

Decía mi señor don Quijote "Que en las cortesías más vale pasarse de más que de menos". No es por cortesía si no por agradecimiento a su comportamiento y a todo lo que me enseñó, que me atrevo a glosar algunos aspectos de mis vivencias dentro del Servicio de Urología de la Fundación Jiménez Díaz que tan acertadamente dirigía. No me pasaré más y seguro me quedaré en el menos, porque $\mathrm{D}$. Luis $\mathrm{Ci}$ fuentes merece un análisis muy profundo de su obra científica y contribución al desarrollo de la urología española.

Ya en mis años de estudiante en la Facultad de Medicina de Cádiz, me incliné desde muy temprano por la cirugía general y en particular por 
la urología. Conocí al Dr. Federico Rodríguez Rubio discípulo directo del Dr. Cifuentes y con quién di los primeros pasos en esta especialidad.

Terminada mi carrera salí en busca de $D$. Luis con dos cartas de presentación bajo el brazo, la del discípulo Federico y la del Profesor Arcelus a la postre mi maestro en cirugía general.

Mi entrevista con D. Luis se llevó a cabo a mediados del mes de Septiembre de 1.969. Me recibió en su consulta de la madrileña calle Montesquinza 20 a las 20 horas de una noche lluviosa y desapacible. Me presenté sin previo aviso (como un enfermo más), y con el lógico nerviosismo que esto impone y sin saber la respuesta que iba a obtener.

Me recibió atentamente como después pude comprobar que era su comportamiento habitual, me escuchó, reflexionó y al día siguiente me citó en la Fundación en el propio servicio de urología. Días después me incorporé en su grupo en calidad de médico residente becario, gracias a una beca que él personalmente solicitó en el Instituto de Cultura Hispánica por mi condición de médico extranjero Hispanoamericano.

Conviví en el servicio de urología de la Clínica de la Concepción durante 3 años, que por aquella época duraba la especialidad, con $D$. Luis y su equipo, los Drs. C. Alférez Villalobos, R. Vela Navarrete y los queridos y ya desaparecidos D. Victoriano Molina y Enrique García de la Peña. Conocí y compartí esos años de especialidad con su hijo Luis que cursaba por entonces el último año de su residencia, con Enrique García Cuerpo, Antonio Berenguer, José Antonio Avellana y a los que más tarde se fueron incorporando, Ricardo Espuelas, José Luis Rodríguez Miñón-Cifuentes y Rafael Díaz González, todos ellos hoy conocidos y prestigiosos urólogos.

\section{Don Luis Cifuentes Delatte como Maestro}

Le gustaba enseñar, trasmitir sus conocimientos a los demás y doy fé que lo lograba, yo diría que era apasionado en la trasmisión del saber.

Estaba siempre dispuesto a responder a cuantas preguntas se le formularan y a convencer a su interlocutor, tanto durante las sesiones clínicas como fuera de ellas. En los temas que más le apasionaban (tumores vesicales, cistitis y cistopatías, litiasis y sedimento urinario) no dejaba pasar el mínimo detalle. Era obligatorio en el servicio, a todo paciente litiásico mirarle el sedimento y comentarlo durante la presentación de enfermos. No se le escapaba nunca la pregunta de rigor ante un enfermo con esa patología ¿̇ qué se ve en su sedimento?.

Bajo sus enseñanzas nos inculcó el empleo de microscopio de contraste de fases para tal menester. Los que fuimos testigos de aquello, sabemos que con esa sencilla prueba y conociendo la morfología de los cristales del sedimento urinario, se intuían diagnósticos de enfermedades metabólicas como la cistinuria, la composición química de los cálculos (ácido úrico, oxalato cálcico y fosfato amónico magnésico entre otros), pues de la estructura íntima cristalográfica ya se ocupaba él de estudiarla junto a su equipo de investigación, mediante los métodos más actuales y que no es momento de referirlos.

En las sesiones clínicas además de enseñar, interrogaba y ayudaba a razonar un diagnóstico hasta conseguir el objetivo terapéutico mejor para el paciente, basado en los datos clínicos, exploratorios y radiológicos. No existía todavía la ecografía, la T.A.C., ni la R.N.M., por lo que los diagnósticos se basaban más en los datos de la historia clínica, exploratorios y en la U.I.V. Esto le llevó a ser un gran clínico, reconocido por toda su escuela. Como se decía antiguamente, D. Luis tenía "buen ojo clínico" que lo llevaban a diagnósticos sorprendentes.

Colaboraba con la Asociación Española contra el cáncer y llegó a elaborar una de las fichas más completas para el estudio de los tumores vesicales. Durante mis tres años estuve dedicado a rellenarlas, tanto en la clínica como en su consulta privada junto al Dr. Palencia, colaborador íntimo de Don Luis en su consulta.

Aparte de buen cirujano era un maravilloso endoscopista, pionero en España y reconocido internacionalmente. En el quirófano, se disfrutaba cuando se le veía operar tumores vesicales o hipertrofias de próstata por vía endoscópica. Aprendíamos "viendo desde fuera", pues a diferencia de lo que hoy en día se consigue mediante el aprendizaje con monitores, en aquellos tiempos existían ópticas de enseñanza de campo de visión reducido y calidad discutible. Sus operaciones las "retrasmitía" con tanto entusiasmo y vehemencia que nos hacía sentir los verdaderos protagonistas de aquellas intervenciones. No se me olvida su expresión de júbilo al terminar unas de estas operaciones "estupendo".

Recordamos aquellas dos figuras de su libro sobre cirugía endoscópica, en donde decía que el pedal se debía pisar con pie de pluma y no con pie de elefante como tan gráficamente lo representaba, dando a entender la sutileza con la que se deben llevar este tipo de intervenciones. 
En definitiva $\mathrm{D}$. Luis cumplía con aquella sagrada misión cual era el magisterio, del que sus discípulos siempre le estaremos agradecidos y del cual los enfermos son los más favorecidos.

\section{Don Luis Cifuentes Académico y Científico}

Sin equivocarnos se puede decir que $D$. Luis Cifuentes ha sido una de las figuras más brillantes en la producción científica de la urología española del siglo XX.

Contribuyó al desarrollo y difusión del saber urológico, fundador en 1.944, junto con los Drs. Puigvert y Pérez Castro de la revista "Archivos Españoles de Urología".

Sin mencionar sus innumerables artículos, fácilmente consultables con los medios actuales, el Dr. Cifuentes fue autor de grandes obras que han servido y sirven a los estudiosos de la urología y que le convierten en un número uno dentro de los líderes de opinión.

Sus libros sobre "Cistitis y Cistopatías" (1.949), "Cirugía Urológica Endoscópica" (1.962), "Composición y estructura de los cálculos urinarios" y monografías como "El laboratorio del urólogo", han constituido obras escritas con solidez y maestría, solamente posible realizar por un estudioso y gran investigador como fue D. Luis. Sus pensamientos, teorías y enseñanzas, siguen aún hoy en día en plena vigencia y aceptación por la comunidad urológica.

Su ponencia al Congreso Nacional de Urología celebrado en Zaragoza sobre "Vejiga Neurógena", sirvió de guía e ilustración para el conocimiento y desarrollo posterior de la neurourología y que hoy en día ha sufrido tan grandes e importantes innovaciones no sólo en los métodos diagnósticos sino también en los terapéuticos. Muchos de sus discípulos siguen perpetuando su obra en el campo de la litiasis, de la neurourología, la uro-oncología entre otras y otros muchos han alcanzado el reconocimiento académico, científico y asistencial en la urología nacional.

La personalidad científica de D. Luis Cifuentes brilló con luz propia gracias a su tesón, esfuerzo y convicción personal. Estos méritos lo llevaron a ocupar un sillón en la Real Academia Nacional de Medicina, sitio reservado a los mejores y que no sólo debe enorgullecer a sus discípulos sino a la urología española en general.

Estoy seguro que la urología española seguirá dando al mundo hombres con mucho talento, ingenio y virtuosismo que sigan haciendo de nuestra especialidad un referente en el mundo, como así fue el pensamiento y el deseo de D. Luis Cifuentes Delatte. 